\title{
Evidence for cross-talk between the LH receptor and LH during implantation in mice
}

\author{
Virginie Gridelet ${ }^{\mathrm{A}, \mathrm{E}}$, Marie Tsampalas ${ }^{\mathrm{A}}$, Sarah Berndt ${ }^{\mathrm{B}}$, Marie-Thérèse \\ Hagelstein $^{\mathrm{A}}$, Chantal Charlet-Renard ${ }^{\mathrm{A}}$, Valérie Conrath ${ }^{\mathrm{C}}$, Fabien Ectors ${ }^{\mathrm{C}}$, \\ Fabian Hugé ${ }^{\mathrm{A}}$, Carine Munaut ${ }^{\mathrm{B}}$, Jean-Michel Foidart ${ }^{\mathrm{B}, \mathrm{D}},{ }^{\prime}$ Vincent Geenen $^{\mathrm{A}}$ \\ and Sophie Perrier d'Hauterive ${ }^{\mathrm{A}, \mathrm{D}}$ \\ A University of Liege, Center of Immunology, Institute of Pathology, Centre Hospitalier \\ Universitaire B-23, 4000 Liege-Sart Tilman, Belgium. \\ ${ }^{\mathrm{B}}$ University of Liege, Laboratory of Tumor and Development Biology, Institute of Pathology, \\ Centre Hospitalier Universitaire B-23, 4000 Liege-Sart Tilman, Belgium. \\ C University of Liege, Transgenic Platform, Groupe Interdisciplinaire de Génoprotéomique \\ Appliquée, Centre Hospitalier Universitaire B34, 4000 Liege-Sart Tilman, Belgium. \\ DUniversity of Liege, Centre for Assisted Medical Procreation, Centre Hospitalier Regional \\ de la Citadelle, 4000 Liege, Belgium. \\ ${ }^{\mathrm{E}}$ Corresponding author. Email: virginie.gridelet@ulg.ac.be
}

\begin{abstract}
The present study investigated the first interaction that occurs between the blastocyst and endometrium during implantation. Given the ethical objections to studying implantation in humans, a mouse model was used to study the dialogue between luteinising hormone (LH) and luteinising hormone receptor (LHCGR). Several studies performed on LHCGR-knockout mice have generated controversy regarding the importance of the dialogue between LH and LHCGR during implantation. There has been no demonstration of a bioactive LH-like signal produced by the murine blastocyst. The first aim of the present study was to examine and quantify, using radioimmunoassay, the generation of a bioactive LH signal by the murine blastocyst. We went on to examine and quantify endometrial Lhcgr expression to validate the mouse model. Expression of LHCGR in mouse uteri was demonstrated using immunohistochemistry and western blot analysis. To quantify the expression of $L h$ in the mouse blastocyst and Lhcgr in the endometrium, reverse transcription-polymerase chain reaction (RT-PCR) and real-time quantitative (q) RT-PCR were performed. The results demonstrate that Lhcgr expression in $\mathrm{BALB} / \mathrm{c}$ mouse endometrial epithelium is increased at the time of implantation and indicate that LHCGR may contribute to the implantation process. In support of this hypothesis, we identified a bioactive LH signal at the time of murine blastocyst implantation.
\end{abstract}

Additional keywords: embryo signal, endometrium, LHCGR.

Received 21 September 2011, accepted 9 April 2012, published online 29 May 2012

\section{Introduction}

Implantation is a very complex and coordinated process whereby the trophoblast establishes close contact with a specialised tissue contributed by the mother called the endometrium (Aplin 2000; Aplin and Kimber 2004). Normal implantation is required for a successful pregnancy. Specifically, the following two fundamental conditions are essential: (1) the embryo must undergo a series of complex developmental processes during its transport through the Fallopian tube; and (2) in parallel, the endometrium must achieve adequate receptive status, called the 'implantation window' (Psychoyos 1986), which is the optimal period for embryo implantation (Lessey 2000; Sunder and Lenton 2000). Both conditions are necessary to initiate intimate dialogue between the blastocyst and the endometrium (Carson et al. 2000; Paria et al. 2002). To date, the implantation window has not been molecularly defined; however, several potentially defining factors have been identified, including growth factors, cytokines, hormones, extracellular matrix proteins and related enzymes, which are collectively produced by embryonic and maternal tissues of uterine and extrauterine origins (Ghosh and Sengupta 1998; Norwitz et al. 2001; Pan et al. 2006). In addition, the opposing tissue must express cognate receptors for each of these molecules so that implantation cross-talk can occur. Obviously, the study of implantation is not ethically possible in humans and therefore has to be investigated indirectly through the use of animal models or in vitro models. Therefore, small 
animal models with a short gestation that is molecularly similar to that of human gestation and that can be manipulated genetically provide an ideal system in which to study the molecular details of the implantation cascade.

At present, the implantation event itself is the only definitive marker of the implantation window and is associated with the appearance of human chorionic gonadotropin (hCG) in the maternal bloodstream of humans. This hormone is a specific embryonic mediator that announces the embryo's presence to the maternal organism. Transcription of hCG begins before implantation (Jurisicova et al. 1999), as shown in a study in which the hCG production in fluid that was removed from in vitro-cultured embryos was detected as soon as $170 \mathrm{~h}$ after insemination (Fishel et al. 1984). In addition, the results of recent studies demonstrate that hCG plays a crucial role in regulating endometrial cell differentiation and the implantation process; it not only participates in these processes via its endocrine role, but also in a paracrine manner at the maternalfetal interface (Han et al. 1999; Cameo et al. 2004; Afshar et al. 2007; Licht et al. 2007). Blastocyst hCG increases endometrial secretion of proimplantatory leukaemia inhibitory factor (LIF; Perrier d'Hauterive et al. 2004) and macrophage-colony stimulating factor (M-CSF; Licht et al. 2001), increases stromal COX2 (cyclo-oxygenase 2) expression (Han et al. 1996) and reduces the expression of the decidual marker IGF-BPI (insulinlike growth factor binding protein 1) during the late secretory phase (Licht et al. 2002; Fluhr et al. 2006). Blastocyst hCG also increases the production of vascular endothelium growth factor (VEGF) by the endometrial epithelium and stimulates endometrial angiogenesis, suggesting that hCG actively participates in placental development (Zygmunt et al. 2002; Berndt et al. 2006). Finally, the fetal allograft contributes to its tolerance by the competent maternal immune system via the FASFAS ligand pro-apoptosis system (Kayisli et al. 2003), its inhibitory actions on endometrial interleukin (IL)-6 (Perrier d'Hauterive et al. 2004) and complement C3 and C4 factors (Sherwin et al. 2007) and by stimulating maternal regulatory $\mathrm{T}$ cells (Zenclussen et al. 2006). Another example of an immunomodulatory property of hCG is its capacity to downregulate effector cells, including $\mathrm{T}$ helper $(\mathrm{T} \mathrm{H}) 1$ cells, $\mathrm{CD} 8^{+} \mathrm{T}$ cells and macrophages, and to increase the $\mathrm{CD} 4^{+} \mathrm{CD} 25^{+} / \mathrm{CD} 4^{+} \mathrm{T}$ cell ratio, as shown in non-obese diabetic (NOD) mice (Khan et al. 2001; Khil et al. 2007).

In contrast, the first maternal tissue encountered by the embryo is the endometrial epithelium, which expresses the LH/chorionic gonadotropin receptor (LHCGR; Perrier d'Hauterive et al. 2004). The LHCGR system was first described in gonadal (ovaries and testis) and non-gonadal tissues in porcine (Ziecik et al. 1986), rabbit (Jensen and Odell 1988) and murine (Mukherjee et al. 1994) endometrium.

Together, these observations suggest that the LHCGR system is intimately involved in implantation processes, particularly in humans, where hCG is the specific embryo signal sent to the mother. The cross-talk between hCG and the LHCGR is likely critical for the early steps of implantation, but is very difficult to study in humans for obvious ethical reasons. Therefore, the importance of the LHCGR system during implantation processes has been approached via a murine model.
The main objective of the present study was to investigate the existence of LH-LHCGR dialogue at the maternal-fetal interface during implantation in mice. The existence of this crosstalk is crucial for the validation of the mouse model as a good non-human implantation model for the study of LH-LHCGR communication. Therefore, we first identified and quantified the presence of an LH-like signal produced by the mouse blastocyst. We then demonstrated the bioactivity of this signal by assessing the production of testosterone by Leydig cells. Finally, endometrial Lhcgr expression throughout the oestrous cycle of the $\mathrm{BALB} / \mathrm{c}$ mouse was examined and quantified to determine whether higher Lhcgr expression corresponded to the supposed period of embryo implantation. A comprehensive examination of endometrial LHCGR expression in mice and identification of a bioactive LH-like signal are crucial first steps to characterise the LHCGR system in the mouse and may lead to the elucidation of the regulatory pathways involved in the early adhesion and invasion processes of implantation.

\section{Materials and methods}

\section{Animals}

BALB/c mice (5-12 weeks old) and C57 male mice (2-3 months old) were obtained from the University of Liege Animal Center and investigations were conducted with the approval of the University of Liege Ethics Committee for the care of experimental animals (no. 2006/412 and no. 2006/561). Mice were housed under a 12-h light-dark cycle in a temperaturecontrolled environment, with food and water available ad libitum. Endometrial tissue or granulosa cells served as the positive control for reverse transcription-polymerase chain reaction (RT-PCR) and RNA samples were obtained from BALB/c female mice. Testes and ovaries obtained from BALB/c mice ( 5 weeks old) were used as a positive control for LHCGR in western blot analyses and immunohistochemistry. Leydig cells used for the LH bioassay were obtained from C57 male mice.

Six-week-old inbred FVB/Nico female mice (Charles River, Saint- Germain sur l'Arbresle, France) were induced to superovulate with intraperitoneal injections of pregnant mare's serum gonadotropin (PMSG; 3.5 IU; Intervet, Boxmeer, The Netherlands) followed $46 \mathrm{~h}$ later with an injection of $5 \mathrm{IU}$ hCG (Intervet). The mice were then mated with FVB/Nico male mice. Zygotes were obtained on Day 1 after hCG injection. Only zygotes with two clearly visible pronuclei were cultured further. Embryos were cultured in groups of 20 or 25 , incubated at $38.0 \pm 0.5^{\circ} \mathrm{C}$ in a humidified atmosphere of $5 \% \mathrm{CO}_{2}$ in air and allowed to develop in $50-\mu \mathrm{L}$ droplets of M16 medium under mineral oil (Fertipro, Beemem, Belgium) until Day 5 or Day 6. At this stage, approximately $90 \%$ of embryos had reached the blastocyst stage. To cover the period of embryo development around their implantation (i.e. from Day 5 to Day 10), blastocysts were further cultured in G2V5Plus (Vitrolife, Göteborg, Sweden) medium. The media were harvested and conserved for analyses every 2 days, from Days 5 or 6 to Day 9 or 10. Some cultures were stopped to kill embryos every day from Day 5 to Day 10. Consequently, embryos and samples of the culture medium were obtained daily from Day 5 to Day 10 and were stored at $-20^{\circ} \mathrm{C}$ until the LH radioimmunoassay (RIA) was performed (Table 1). Blastocysts were sonicated 
Table 1. Number of embryos killed and used for each analysis on the days of interest

\begin{tabular}{lrrrrrrr}
\hline & Day 5 & Day 6 & Day 7 & Day 8 & Day 9 & Day 10 & Total no. embryos \\
\hline LH assay & 1100 & 1700 & 1400 & 1200 & 1600 & 1100 & 8100 \\
LH bioactivity & 200 & 400 & 300 & 400 & 400 & 400 & 2100 \\
Lh RNA expression & 0 & 500 & 0 & 0 & 0 & 0 & 500 \\
\hline
\end{tabular}

for $30 \mathrm{~s}$, then the lysates were centrifuged at $10000 \mathrm{~g}$ for $10 \mathrm{~min}$ at $4^{\circ} \mathrm{C}$; the resulting supernatants were harvested immediately before performing the RIA. Uterine horns and blood samples from pregnant and non-pregnant mice were obtained from the FVB/Nico female mice to study implantation sites.

\section{Vaginal smears}

Vaginal smears were prepared to determine the stage of the oestrous cycle. The mouse vaginas were flushed with $20 \mu \mathrm{L}$ Dulbecco's phosphate-buffered saline (DPBS; Lonza, Verviers, Belgium), which was then deposited on a slide and stained with haematoxylin-eosin (HE) and examined at $\times 200$ magnification by light microscopy.

\section{Preparation of mouse tissues and cells}

To study implantation sites and LH production during pregnancy, mice were killed on Day 7 of pregnancy by cervical dislocation. Blood samples were taken and the uterine horns were exposed by dissection. Implantation sites were collected by cutting the uteri on either side of each decidual swelling. The embryos were extracted from these implantation sites. All the implantation sites for a given female were pooled, as were all the embryos from the same female. Implantation sites and embryos were stored in M16 medium until the LH RIA was performed. Blood samples were centrifuged to obtain serum, which was stored until the LH RIA. Immediately before performing the RIA, embryos and implantation sites were sonicated for $30 \mathrm{~s}$ and then centrifuged at $10000 \mathrm{~g}$ for $10 \mathrm{~min}$ at $4^{\circ} \mathrm{C}$; the resulting supernatants were harvested for the RIA.

The Leydig cells used for the LH bioassay were obtained from C57 mouse testes, as described by Dufau et al. (1974). Briefly, testes were dispersed mechanically in M199 medium (Lonza; six testes per $10 \mathrm{~mL}$ ) using sharp scissors, followed by mixing with a magnetic stirrer at room temperature for $10 \mathrm{~min}$. After filtration through nylon mesh (mesh size $100 \mu \mathrm{m}$ ), the cell suspension was washed twice with M199 medium supplemented with $0.1 \%$ bovine serum albumin (BSA; Sigma-Aldrich, Bornem, Belgium), 0.125 mM 1-methyl-3-isobutyl-xanthine (MIX; Sigma-Aldrich) and $20 \mathrm{mM}$ HEPES (Sigma-Aldrich) immediately before the bioassay. Cells obtained using this technique are predominantly Leydig cells, as described previously (Dufau et al. 1974; Ding and Huhtaniemi 1989).

To obtain endometrial tissue, mice were killed by cervical dislocation and dissected to expose the uterine horns, which were opened immediately in situ along the anti-mesometrial axis. One horn from each mouse was frozen in Tissue-Tek (Labonord, Templemars, France) and stored at $-80^{\circ} \mathrm{C}$ for immunohistochemistry; the second horn was used for mRNA extraction and placed in $1.5 \mathrm{~mL}$ Hanks' balanced salt solution (Lonza) containing penicillin $\left(10000 \mathrm{IU} \mathrm{mL}^{-1}\right)$ and streptomycin $\left(10000 \mu \mathrm{g} \mathrm{mL}^{-1}\right.$; HBSS-AB). The endometrium was isolated according to the method described by Buxton and Murdoch (1982). Briefly, the endometrium was isolated accomplished by digesting the tissue for $45 \mathrm{~min}$ at $37^{\circ} \mathrm{C}$ in $5 \mathrm{mg} \mathrm{mL}^{-1}$ collagenase 1a (Sigma-Aldrich) diluted in HBSS-AB. The tissue was gently pipetted to disperse the cells during collagenase digestion. Then, $3 \mathrm{~mL}$ fresh HBSS$\mathrm{AB}$ was added to quench the reaction and the suspension was passed through a silk filter. The filtered suspension was then centrifuged for $5 \mathrm{~min}$ at $360 \mathrm{~g}$. The pelleted cells were washed twice with HBSS-AB and centrifuged at $360 \mathrm{~g}$ for $5 \mathrm{~min}$. The number of viable cells was then determined by Trypan blue dye exclusion. Samples were transferred into an Eppendorf tube and centrifuged at $360 \mathrm{~g}$ for $5 \mathrm{~min}$. A volume of $500 \mu \mathrm{L}$ of RNeasy Lysis Buffer (RLT; Qiagen, Valencia, CA, USA) containing 1\% $\beta$-mercaptoethanol (Merck, Darmstadt, Germany) was added to the cells, which were then stored at $-80^{\circ} \mathrm{C}$ until RNA extraction.

The testis and ovaries used as positive controls for western blot analysis were obtained from BALB/c mice and were dissected using the same protocol as used for uterine horn removal. The dissected testes and ovaries were homogenised, incubated in radioimmune precipitation assay buffer and stored at $-20^{\circ} \mathrm{C}$ until protein extraction.

To obtain the pancreas, mice were killed by cervical dislocation and the pancreas dissected. The excised pancreas was homogenised, incubated in RLT containing $1 \% \beta$-mercaptoethanol and then stored at $-80^{\circ} \mathrm{C}$ until RNA extraction.

Ovaries were treated to obtain mouse granulosa cells. Female mice were stimulated with one injection of PMS-G (SigmaAldrich; $5 \mathrm{IU}$ per $0.1 \mathrm{~mL}$ ) $48 \mathrm{~h}$ before being killed by cervical dislocation and dissected to expose the ovaries. Each ovary was placed in RPMI medium (Lonza) with 1\% L-glutamine (Lonza), perforated and then incubated in 199 medium (Lonza) containing $6.8 \mathrm{mM}$ EGTA and $0.2 \%$ BSA (Sigma-Aldrich) for $10 \mathrm{~min}$. The ovaries were then incubated in M199 medium containing $1.8 \mathrm{mM}$ EGTA, $0.2 \% \mathrm{BSA}$ and $0.5 \mathrm{M}$ sucrose for $3 \mathrm{~min}$, washed three times with RPMI-1\% L-glutamine and homogenised in RPMI-1\% L-glutamine and 10\% fetal calf serum (FCS). The resulting suspension was passed through a silk filter. The number of viable cells was determined by Trypan blue dye exclusion and cells were resuspended in RLT-1\% $\beta$-mercaptoethanol and stored at $-80^{\circ} \mathrm{C}$ until RNA extraction.

The pituitary gland was extracted after mice had been killed by cervical dislocation and the extract was stored in RLT-1\% $\beta$-mercaptoethanol at $-20^{\circ} \mathrm{C}$ until RNA extraction.

\section{Radioimmunoassay for $\mathrm{LH}$}

The LH concentrations in $100 \mu \mathrm{L}$ culture medium were determined using a double-antibody method and a commercially 
available RIA kit (mLHRia), kindly supplied by the National Institutes of Health (Dr A. F. Parlow, National Institute of Diabetes and Digestive and Kidney Diseases, National Hormone and Peptide Program, Torrance, CA, USA). Rat LH-I-10 (AFP11536B) was labelled with ${ }^{125}$ I using the chloramine-T method and the hormone concentration was calculated using the mouse LH reference preparation (AFP-5306A) as the standard. Intraand interassay CVs were less than $4 \%$ and $7 \%$, respectively. The sensitivity of the assay in culture medium was $4 \mathrm{pg} 100 \mu \mathrm{L}^{-1}$. The remaining culture medium and embryos were pooled according to the day of gestation and stored at $-20^{\circ} \mathrm{C}$ until the bioassay.

\section{Bioactivity of $\mathrm{LH}$}

To determined LH bioactivity, a procedure described previously by Dufau et al. (1974) and Ding and Huhtaniemi (1989) was used. Briefly, Leydig cells were seeded to obtain a final density of 50000 cells per well in $100 \mu \mathrm{L}$ M199 medium supplemented with $0.1 \%$ BSA, $0.125 \mathrm{mM}$ MIX and $20 \mathrm{mM}$ HEPES. The incubations were performed in triplicate at $34^{\circ} \mathrm{C}$ for $3 \mathrm{~h}$ with shaking at 150 cycles per min in a $95 \% \mathrm{O}_{2} / 5 \% \mathrm{CO}_{2}$ atmosphere. An $\mathrm{LH}$ standard curve diluted in M16 medium was established that contained defined amounts of LH ranging from 15.6 to $500 \mathrm{pg} \mathrm{mL}^{-1}$ (AFP5306A). Each sample corresponding to a particular condition (from Day 5 to Day 10) contained $100 \mu \mathrm{L}$ of the interstitial cell suspension and $100 \mu \mathrm{L}$ of the LH standard or a $100-\mu \mathrm{L}$ aliquot of the corresponding embryo culture medium. Samples contained an average of $40 \mathrm{pg} \mathrm{mL}^{-1} \mathrm{LH}$ in M16 medium or G2V5Plus, as described above. Control samples contained a cell suspension in M199 medium, M16 or G2V5Plus.

After incubation, the cells and culture medium were harvested from the wells and centrifuged at $435 \mathrm{~g}$ for $10 \mathrm{~min}$. Then, $150 \mu \mathrm{L}$ supernatant was removed from each sample and stored at $-20^{\circ} \mathrm{C}$ until the testosterone assay.

\section{Testosterone RIA}

Testosterone concentrations were determined by direct RIA using the RIA Testosterone Direct Kit (Beckman Coulter, Villepinte, France) according to the manufacturer's instructions. The RIA was performed in duplicate. The incubation was performed in duplicate in a $37^{\circ} \mathrm{C}$ water bath for $3 \mathrm{~h}$. Each sample contained $50 \mu \mathrm{L}$ embryo culture medium collected in the bioassay and $500 \mu \mathrm{LI}^{125}$-labelled testosterone. Results are expressed as the amount of testosterone produced by Leydig cells after incubation with embryo culture medium.

The LH bioactivity was calculated using the testosterone curve generated from the known concentrations of LH placed in the Leydig cell cultures. An LH standard curve diluted in M16 medium was generated during the bioassay using defined amounts of LH. The testosterone levels produced by the known concentrations of LH were also determined by the RIA. The results of the assay were used to generate a curve of testosterone production resulting from incubation with $\mathrm{LH}$. For each embryo culture medium sample, the concentration of testosterone as determined by the RIA was reported on this curve. The aim of this calculation was to compare the bioactivity of the LH produced by mouse embryos with the bioactivity of a standard LH (AFP-5306A).

\section{Immunohistochemistry}

Uteri were embedded in Tissue-Tek and frozen at $-80^{\circ} \mathrm{C}$. Sections $(5 \mu \mathrm{m})$ were cut and deposited on slides. The slides were incubated for $2 \mathrm{~min}$ in wash buffer $(1 / 100.5 \mathrm{M} 50 \mathrm{mM}$ Tris $5 \mathrm{mM} \mathrm{HCl}, \mathrm{pH} 7.6,0.9 \% \mathrm{NaCl}, 0.5 \%$ Tween $20,0.2 \% \mathrm{NaN}_{3}$ ) and fixed in $10 \%$ paraformaldehyde for $10 \mathrm{~min}$. The slides were then washed three times in wash buffer for $5 \mathrm{~min}$ and blocked with milk (1.5\% diluted in DPBS) for $30 \mathrm{~min}$. Slides were incubated overnight at $4{ }^{\circ} \mathrm{C}$ with a primary polyclonal goat anti-rat LHCGR antibody (pAb; Tebu-Bio, Boechout, Belgium; $4 \mu \mathrm{g} \mathrm{mL}^{-1}$ ) diluted in $50 \mathrm{mM}$ Tris- $\mathrm{HCl}, \mathrm{pH} 7.6$, and $10 \% \mathrm{NaN}_{3}$. The next day, slides were washed three times for $5 \mathrm{~min}$ and then incubated with a secondary fluorescein-coupled mouse anti-goat IgG $\mathrm{Ab}$ (Sigma-Aldrich) diluted 1:50. After three 5-min washes, the slides were mounted with Vectashield mounting medium (Vector Laboratories, Burlingame, CA, USA). Pancreas sections served as the negative control with $4^{\prime}, 6^{\prime}$-diamidino-2-phenylindole (DAPI)-stained nuclei. The negative control was established using Ig from goat (I5256 Sigma-Aldrich). Testis sections with Leydig cells served as the positive control.

\section{Western blot analysis}

Total cell extracts were prepared by incubating cells in radioimmune precipitation assay buffer $(50 \mathrm{mM}$ Tris- $\mathrm{HCl}, \mathrm{pH} 7.4$; $150 \mathrm{mM} \mathrm{NaCl} ; 1 \%$ Nonidet-P40, $1 \%$ Triton X-100; $1 \%$ sodium deoxycholate; $0.1 \%$ sodium dodecylsulfate (SDS); $5 \mathrm{mM}$ iodoacetamide; $2 \mathrm{mM}$ phenylmethylsulfonyl fluoride). Samples were centrifuged at $10000 \mathrm{~g}$ for $30 \mathrm{~min}$ at $4^{\circ} \mathrm{C}$, the supernatant collected and frozen at $-20^{\circ} \mathrm{C}$. Protein concentrations were determined using the Bradford test (BioRad, Nazareth Eke, Belgium) and $20 \mu \mathrm{g}$ protein was analysed per sample. The extracts were concentrated under reducing conditions and resolved by SDS-10\% polyacrylamide gel electrophoresis (PAGE) and transferred to polyvinylidene fluoride (PVDF) membranes (Immobilon Transfer Membrane; Millipore, Overijse, Belgium). The membranes were exposed to primary antiLHCGR rabbit pAb (1 : 1000; GB-30071; Gentaur, Kampenhout, Belgium) diluted in wash buffer with $2 \%$ BSA. After extensive washing, the membranes were incubated with a secondary goat anti-rabbit antibody (1: 1000; \#7074; Cell Signaling, Danvers, MA, USA). Signals were detected using Fujifilm LAS 4000 (Fujifilm Life Science, Edison, NJ, USA). Testis cell extracts and ovaries cell extracts from wild-type mice served as the positive controls, whereas testis cell extracts from $\mathrm{LH} / \mathrm{hCG}$ receptorknockout (LuRKO) mice, which were generated by disruption of exon 11 of the Lhcgr gene (Zhang et al. 2001a), served as the negative control. Precision Plus Protein Standard Dual Colour (BioRad) standards were used to estimate molecular weight.

\section{RNA extraction for RT-PCR and real-time quantitative RT-PCR}

Total cellular RNA was extracted from tissue samples (endometrium, embryos, pancreas, granulosa, anterior pituitary gland cells) using an RNeasy Mini Kit (Qiagen, Valencia, CA, USA) according to the manufacturer's instructions. Samples were treated with RNase-free DNase (Roche, Mannheim, Germany). The RNA concentrations of the samples were 
Table 2. Sequences of the primers used for quantitative reverse transcription-polymerase chain reaction and the size of the corresponding amplicon $\mathrm{PCR}$, polymerase chain reaction

\begin{tabular}{llc}
\hline Primers & Sequence & PCR product size (bp) \\
\hline$l h c g r$ forward & 5'-GAT-GCA-CAG-TGG-CAC-CTT-C-3' $^{\prime}$ & 185 \\
$l h c g r$ reverse & $5^{\prime}$-TCA-GCG-TGG-CAA-CCA-GTA-G-3' & \\
$l h c g r$ probe & 5'-FAM-CTC-ATC-GCC-ACG-TCA-TCC-TAC-TCA-CT-TAMRA-3' $^{\prime}$ & \\
$l h$ forward & $5^{\prime}$-CAG-TCT-GCA-TCA-CCT-TCA-CC-3' & 259 \\
$l h$ reverse & $5^{\prime}$-ACA-GGC-CAT-TGG-TTG-AGT-CC-3' & 250 \\
$\beta$-Actin forward & $5^{\prime}$-TAA-AGA-CCT-CTA-TGC-CAA-CAC-AGT-3' & \\
$\beta$-Actin reverse & 5'CAC-GAT-GGA-GGG-GCC-GGA-CTC-ATC-3' $^{\prime}$ & \\
\hline
\end{tabular}

determined using a NanoDrop ND-1000 (NanoDrop Products, Wilmington, DE, USA).

For RT-PCR, total RNA ( $\left.50 \mathrm{ng} \mu \mathrm{L}^{-1}\right)$ was reverse transcribed using reverse transcriptase and a Transcriptor First Strand cDNA Synthesis Kit (Roche) according to the manufacturer's instructions. Amplification of cDNA for RT-PCR was performed using a FastStart Taq DNA polymerase kit (Roche) and Eurogentec (Liège, Belgium) primer pairs corresponding to the mouse Lhcgr and $L h$ cDNA sequences. Primers against the $\beta$-actin cDNA sequence were acquired from Invitrogen (Grand Island, NY, USA). The $L h c g r$, $L h$ and $\beta$-actin primers yielded amplified products of 185,259 and $250 \mathrm{bp}$, respectively (Table 2).

The PCR reactions for $L h c g r, L h$ and $\beta$-actin contained $1.5 \mathrm{mM} \mathrm{MgCl} \mathrm{Mg}_{2}$ and $400 \mathrm{nM}$ each of the forward and reverse primers. The PCR cycling conditions for Lhcgr began with an incubation at $95^{\circ} \mathrm{C}$ for $5 \mathrm{~min}$, followed by amplification by 40 cycles of $45 \mathrm{~s}$ at $95^{\circ} \mathrm{C}, 45 \mathrm{~s}$ at $59.5^{\circ} \mathrm{C}$ and $1 \mathrm{~min}$ at $72^{\circ} \mathrm{C}$. The PCR cycling conditions for $L h$ began with an incubation at $95^{\circ} \mathrm{C}$ for $5 \mathrm{~min}$, followed by amplification for 40 cycles of $45 \mathrm{~s}$ at $95^{\circ} \mathrm{C}$, $45 \mathrm{~s}$ at $60^{\circ} \mathrm{C}$ and $1 \mathrm{~min}$ at $72^{\circ} \mathrm{C}$. The PCR cycling conditions for $\beta$-actin began with an incubation at $95^{\circ} \mathrm{C}$ for $5 \mathrm{~min}$, followed by amplification for 30 cycles of $45 \mathrm{~s}$ at $95^{\circ} \mathrm{C}, 45 \mathrm{~s}$ at $55^{\circ} \mathrm{C}$ and $1 \mathrm{~min}$ at $72^{\circ} \mathrm{C}$.

The PCR products were analysed by electrophoresis on $2 \%$ agarose gels. The product size of Lhcgr was estimated using an EZ Load 100 bp Molecular Ruler (BioRad), whereas the product size of $L h$ was estimated using an EZ Load Precision Molecular Mass Standard (BioRad). Lhcgr was also amplified from granulosa cells (positive control) and pancreas (negative control), whereas $L h$ was also amplified from anterior pituitary gland cells as a positive control. To confirm that the PCR products represented mouse Lhcgr and $L h$ transcripts, the PCR products were subjected to sequence analysis using a 3100-Avant Genetic Analyzer from ABI Prism (Applied Biosystems, Carlsbad, CA, USA) by the Laboratory of Human Genetics-CHU (Liege, Belgium). DNA contamination during the PCR was assessed by running a sample in which the cDNA was replaced with water.

Real-time quantitative (q) RT-PCR was used to quantify mRNA in a BioRad iCycler according to the TaqMan method (Holland et al. 1991). Each $25 \mu \mathrm{L}$ reaction for the housekeeping gene $18 \mathrm{~s}$ consisted of $100 \mathrm{ng}+\mathrm{RT}$ sample, $50 \%$ iQ Supermix (BioRad), 5\% Mix Human 18s rRNA 20* (Applied Biosystems) and $25 \%$ nuclease-free water (Ambion, Grand Island, NY, USA). Each $25 \mu \mathrm{L}$ reaction for $\mathrm{Lhcgr}$ consisted of $100 \mathrm{ng}+\mathrm{RT}$ sample,
$50 \%$ iQ Supermix, $2 \mathrm{mM} \mathrm{MgCl}_{2}, 200 \mathrm{nM}$ each primer (Eurogentec), $200 \mathrm{nM}$ probe (Eurogentec) and 10\% nuclease-free water (Table 2). A probe labelled with VIC (emitting fluorescence at $530 \mathrm{~nm}$ ) was used for analysis of $18 \mathrm{~s}$ expression and a probe labelled with FAM (emitting fluorescence at $490 \mathrm{~nm}$ ) was used for analysis of Lhcgr expression. The qPCR programme began with an incubation at $50^{\circ} \mathrm{C}$ for $2 \mathrm{~min}$, followed by $10 \mathrm{~min}$ at $95^{\circ} \mathrm{C}$ and then 40 amplification cycles. Each cycle consisted of denaturation for $15 \mathrm{~s}$ at $95^{\circ} \mathrm{C}$ followed by annealing for $1 \mathrm{~min}$ at $59.5^{\circ} \mathrm{C}$. Target gene expression was determined using the $\Delta \mathrm{Ct}$ comparative $\mathrm{Ct}$ (cycle threshold detection) method to normalise target gene expression against that of $18 \mathrm{~s}$ rRNA expression. Expression of Lhcgr in granulosa cells was used to generate standard curves (with each dilution run in duplicate) for quantification of Lhcgr expression (dilution range: 90 000-370 pg).

\section{Statistical analyses}

Non-parametric tests were used for Lhcgr qPCR data analysis because, in many experiments, the data covered a wide range of values and were not normally distributed. Data were subjected to a Kruskal-Wallis test followed by a Dunn post-test to evaluate differences in Lhcgr expression throughout the oestrous cycle or differences in $t h$ expression and production by embryos in culture. Median differences were considered significant when $P<0.05$. Parametric tests were used to evaluate data on $\mathrm{LH}$ expression and production by embryos in culture and on LH bioactivity on Leydig cells, and the statistical significance of the data was analysed by one-way analysis of variance (ANOVA) with a Tukey post-test. Mean differences were considered significant when $P<0.05$.

\section{Results}

Detection of a bioactive $\mathrm{LH}$ signal in the murine blastocyst at the mRNA and protein levels

To assess $l h$ transcripts produced by the murine embryo, total mRNA was extracted from 500 pooled mouse blastocysts and subjected to RT-PCR. As a positive control, RT-PCR was performed on RNA obtained from pituitary glandular cells. Six days after fertilisation, $l h$ transcription in mouse blastocysts was examined (Fig. 1). The PCR products were sequenced and found to correspond to Mus musculus lh (gi 930344).

Mouse LH was detected by RIA from 5-10 days after fertilisation in blastocysts (each sample contained 100 blastocysts; Fig. $2 a$ ) and in the embryo culture medium (FVB/NICO; 


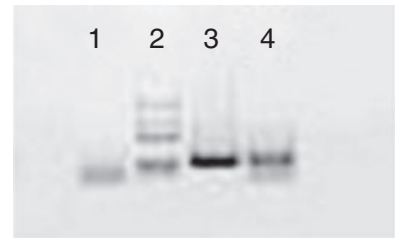

$259 \mathrm{bp}$

Fig. 1. The $l h$ transcripts ( $259 \mathrm{bp}$ ) were detected in mouse blastocysts on Day 6 (Lane 4) after fertilisation. Water (Lane 1) was used as a technical control. The migration front of the primers appears as a fuzzy band in Lanes 1 and 4. Adenohypophysis (Lane 3) served as a positive control. EZ Load Precision Molecular Mass Standard (BioRad, Nazareth Eke, Belgium) was used to estimate the molecular weight scale (Lane 2).

each sample represented LH produced by 50 blastocysts; Fig. $2 b$ ). The mouse blastocyst LH signal remained stable within the embryo from Day 5 to Day 9 (although a slight increase was observed between Day 6 and Day 8), but the quantity of LH produced and secreted by the embryos into the culture medium increased significantly from Day 5 to Day 10.

Mouse LH bioactivity was detected using an in vitro bioassay to measure the production of testosterone by Leydig cells that were stimulated with LH. The LH signal was identical to the signal identified by RIA within blastocysts (Fig. 2c) and in embryo culture medium (Fig. $2 d$ ). The LH bioactivity detected in embryos remained constant between Day 5 and Day 10 after fertilisation. Interestingly, the bioactivity of the LH detected in the embryo culture medium increased significantly $(P<0.001)$ after 7 days of culture. Figure $2 e, f$ shows LH bioactivity detected in both the embryo proper and in the embryo culture medium. The results from this assay revealed that the $\mathrm{LH}$ bioactivity profile within the embryo remains constant (Fig. 2e), whereas the LH bioactivity profile in the embryo culture medium exhibited a highly significant increase from Day 5 to Day 10 (Fig. $2 f$ ).

Experiments conducted on pregnant mice on Day 7 of gestation resulted in the detection of an LH signal in Day 7 serum, implantation sites and embryos (Fig. $2 g$ ), with the highest level of LH observed in the serum.

\section{Morphological characterisation of murine vaginal smears}

To characterise the endometrial biopsies before performing qRT-PCR, sorting criteria were established owing to the absence of appropriate criteria in the literature. First, the mouse oestrous cycle was characterised chronologically by performing vaginal smears on $10 \mathrm{BALB} / \mathrm{c}$ mice four times a day for 5 days. Each stage was identified by assessing epithelial cell morphology and the presence or absence of leucocytes. Using these criteria, the following four stages were easily identified: (1) pro-oestrous stage, characterised by rounded epithelial cells and a discernible nucleus (HE staining); (2) the oestrous stage, characterised by epithelial cells that are keratinised and the absence of a discernible nucleus; (3) a metoestrus stage, characterised by the appearance of leucocytes among the keratinised cells; and (4) dioestrus, in which leucocytes are the major cell population in the vaginal smear $(>50 \%)$ and epithelial cells are again visible.

\section{Localisation of LHCGR in endometrial tissue}

Intense LHCGR labelling was observed in luminal and glandular endometrial epithelium across the stages of the oestrous cycle (Fig. $3 a-d$ ). As expected, we did not observe any LHCGR labelling with the anti-LHCGR pAb in the pancreas, as expected (Fig. $3 e, f)$. As a negative control, we used endometrium at the metoestrous stage incubated with goat IgG (Fig. 3g). Testis incubated with anti-LHCGR served as a positive control.

\section{Western blot analysis of LHCGR protein}

Proteins extracted from the endometrium across the different stages of the oestrous cycle were analysed by western blotting using a primary $\mathrm{pAb}$ against rat LHCGR protein. As shown in Fig. 4, the LHCGR protein was present at every stage of the oestrous cycle with a protein band of approximately $60 \mathrm{kDa}$. Protein lysates from mouse testis cells served as the positive control, whereas protein lysates from LurKO mouse testis cells served as the negative control. To control for gel loading, $\beta$-actin protein levels were also assessed by western blotting (molecular mass $\sim 40 \mathrm{kDa}$ ).

\section{Expression of Lhcgr during the oestrous cycle}

To determine the presence of Lhcgr transcripts, total mRNA was extracted from the intact endometrium and subjected to RT-PCR. The PCR products were analysed by electrophoresis on a $\%$ agarose gel. RNA extracted from granulosa cells and the pancreas was used as a positive and negative control, respectively. DNA contamination was also controlled during PCR by replacing cDNA with water in one sample. $\beta$-Actin was chosen as the housekeeping gene. As shown in Fig. 5, Lhcgr transcription was detected in the mouse endometrium at the four stages of the oestrous cycle. In addition, the PCR products were sequenced and subsequently identified as Mus musculus Lhcgr (gi 94471503).

\section{Quantification of Lhcgr transcripts in endometrial cells}

Endometrial cells were isolated from 79 uteri to quantify Lhcgr expression throughout the oestrous cycle. The endometrium was collected at each of the four stages of the oestrous cycle, namely pro-oestrus $(n=16)$, oestrus $(n=14)$, metoestrus $(n=25)$ and dioestrus $(n=24)$. To quantify Lhcgr transcripts, Lhcgr expression in granulosa cells was used to establish standard curves, with $18 \mathrm{~s}$ used as the housekeeping gene against which Lhcgr expression was normalised (Fig. 5c). The mean level of Lhcgr expression was calculated for each stages of the oestrous cycle.

The mean $( \pm$ s.e.m.) expression of Lhcgr increased from prooestrus $(6.8 \pm 1.1$; median 5.855$)$ to oestrus $(9.9 \pm 2.2$; median 9.041), increased again from oestrus to metoestrus (15.0 \pm 2.2 ; median 11.46) and reached a maximum at dioestrus $(15.1 \pm 2.3$; median 13.72). These increases from one stage to the next were not statistically significant $(P>0.05)$, but the difference between metoestrus and pro-oestrus was significant $(P=$ 0.00257). In addition, a significant decrease in Lhcgr expression was observed between dioestrus and the following pro-oestrus stage $(P=0.0245)$. 
(a)

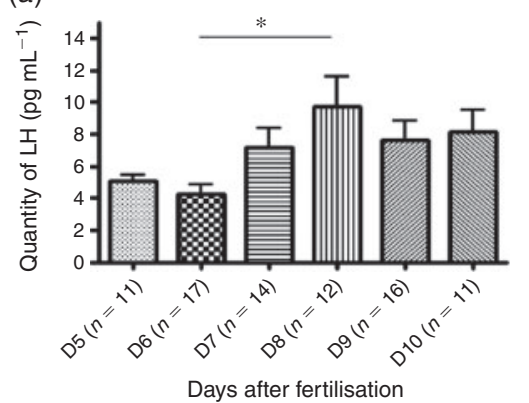

(c)

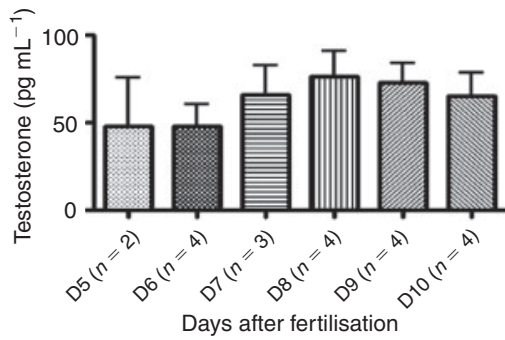

(e)

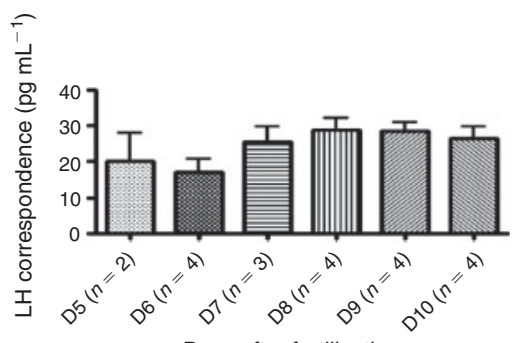

(g)

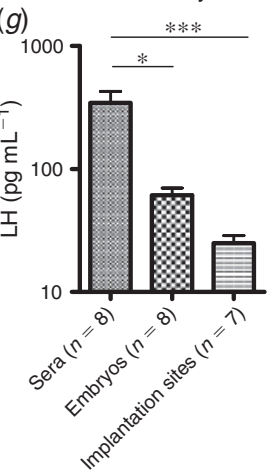

(b)

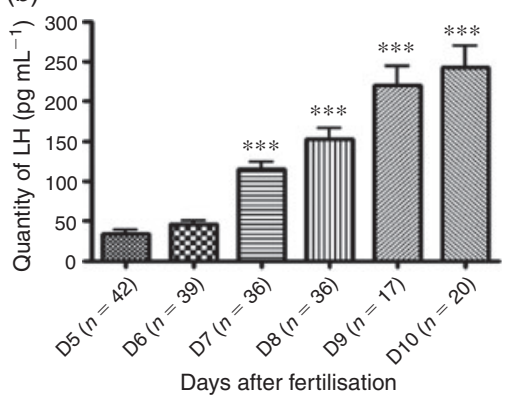

(d)

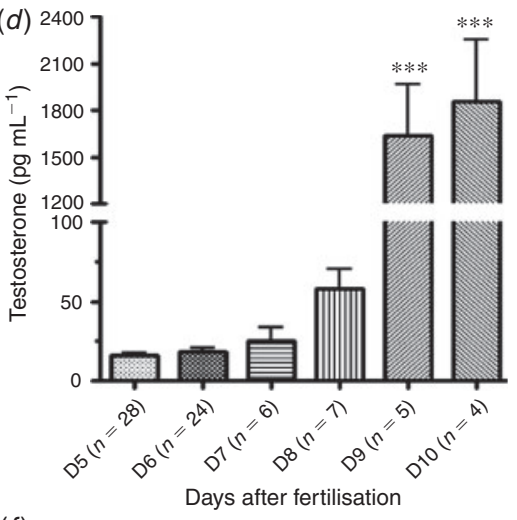

$(f)$

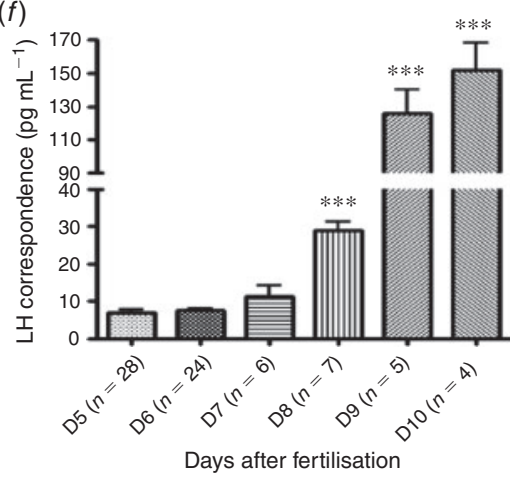

Fig. 2. Quantification of LH in (a) mouse blastocysts (100 per sample) and (b) blastocyst culture medium (50 per sample) from Day (D) 5 to D10 after fertilisation (during implantation). $(c, d)$ Results of the testosterone assay showing LH bioactivity from mouse blastocysts $(c)$ and blastocyst culture medium $(d)$ from D5 to D10 after fertilisation. $(e, f)$ LH bioactivity determined by the bioassay of LH on Leydig cells for mouse blastocysts $(e)$ and blastocyst culture medium $(f))$ from D5 to D10 after fertilisation. ( $g$ ) Quantification of LH expression in pregnant mice on gestation Day 7. Each sample represents one mouse for which all embryos and implantation sites were pooled. The LH concentrations decreased in the sera and embryos between early and late day of the study, whereas concentrations at implantation sites were stable. Data are expressed as mean \pm s.e.m. $* P<0.05,{ }^{* * *} P<0.001$. 

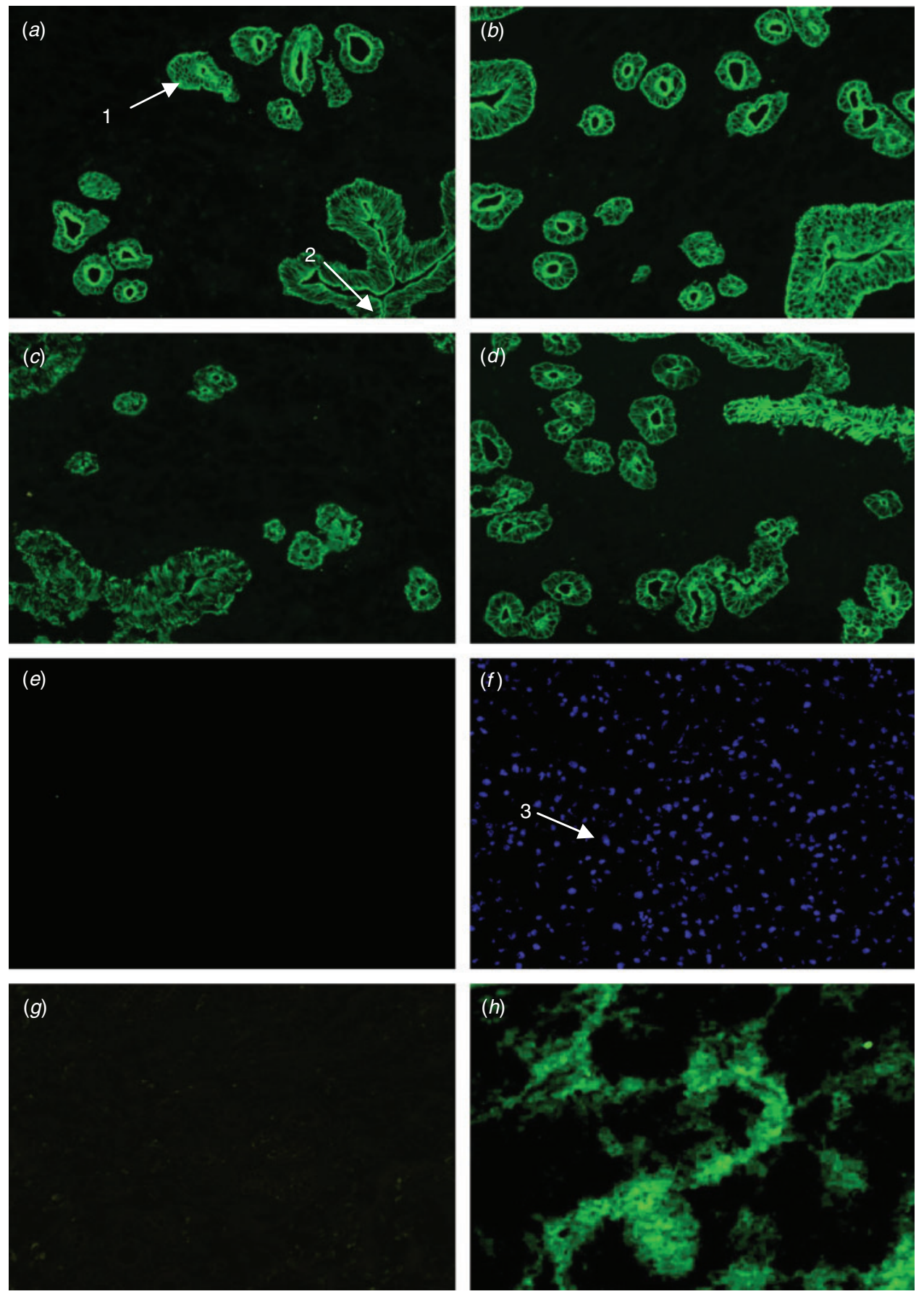

Fig. 3. Localisation of LH/choriogonadotropin receptor (LHCGR) protein in the cycling murine uterus, the pancreas (negative control) and in the testis (positive control). Glandular (Arrow 1) and luminal (Arrow 2) epithelium labelled with primary goat polyclonal antibodies $(\mathrm{pAb})$ raised against rat LHCGR and a secondary fluorescein-coupled rabbit pAb to goat IgG. (a) Pro-oestrus, $(b)$ oestrus, $(c)$ metoestrus, $(d)$ dioestrus, $(e)$ pancreas incubated with anti-LHCGR $\mathrm{pAb},(f)$ pancreas with $4^{\prime}, 6^{\prime}$-diamidino-2-phenylindole-stained nuclei (Arrow 3), and $(g)$ endometrium at the metoestrus stage incubated with goat IgG. $(h)$ The testis served as a positive control. Original magnification $\times 200$.

\section{Discussion}

The specific interaction between blastocyst-derived hCG and endometrial LHCGR constitutes a fundamental exchange that highlights the molecular dialogue at the maternal-fetal interface.
According to our previous observations and those of other groups, hCG plays important paracrine roles in implantation, angiogenesis and immune tolerance (Perrier d'Hauterive et al. 2004, 2005; Edwards 2006; Licht et al. 2007; Rao and Lei 2007). Because of 


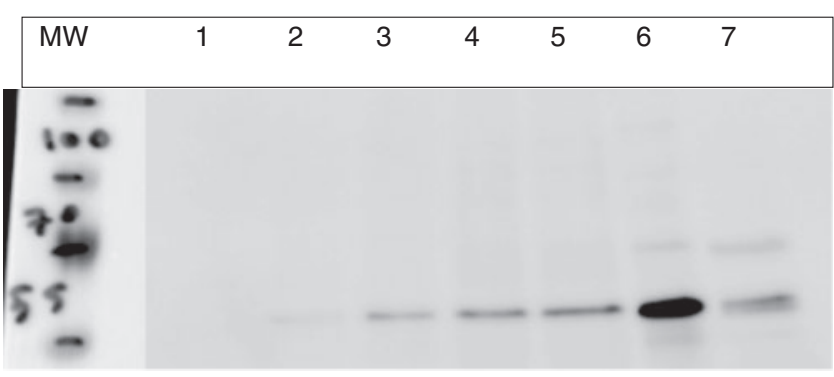

Fig. 4. Expression of LH/choriogonadotropin receptor(LHCGR) in mouse endometrium throughout the oestrous cycle (one mouse each). The LHCGR band is located at approximately $60 \mathrm{kDa}$. Primary rabbit anti-LHCGR rabbit polyclonal antibody and secondary goat anti-rabbit antibody were used. Lane 1, testis from a LHCGR-knockout mouse as a negative control; Lane 2, pro-oestrus; Lane 3, oestrus; Lane 4, metoestrus; Lane 5, dioestrus. The testis (Lane 6) and ovary (Lane 7) from a wild-type mouse served as positive controls. MW, molecular weight scale.

evidence indicating that LHCGR expression peaks during the implantation window in women and is the receptor of a specific embryo signal (V. Gridelet, S. Berndt, M. Tsampalas, V. Geenen and J. M. Foidart, unpubl. obs.), we have hypothesised that LHCGR may be an important new biomarker of that crucial period. To avoid ethical polemics inherent to the study of implantation in human females, we have used the murine model to explore the impact of LH-LHCGR cross-talk during implantation. The presence of a bioactive LH/hCG-like signal during the implantation window in mice favours this model because it shows that there is great similarity between mouse and human implantation. The aims of the present study were to determine whether mice generate a bioactive $\mathrm{LH} / \mathrm{hCG}$-like signal that could have an impact on implantation as is observed in humans and to investigate and quantify endometrial LHCGR expression throughout the oestrous cycle in the $\mathrm{BALB} / \mathrm{c}$ mouse at both the protein and mRNA levels.

We have demonstrated, for the first time, the presence of an LHCGR ligand/signal in mouse trophoblast cells. We have gone on to show that the murine blastocyst expresses and produces an LH signal very early during development, before implantation, as demonstrated in human development by Fishel et al. (1984), and we have demonstrated that this LH signal is clearly bioactive. To our knowledge, this is the first demonstration of the production of a bioactive LH signal by the mouse embryo. This demonstration indicates that the mouse may be a good model in which to study the role and impact of LHCGR signalling during implantation. Moreover, we detected LH in vivo on gestation Day 7 in sera, embryos and implantations sites. There was a higher concentration of LH in the serum than in the embryos and at the implantation sites. These results do not mean that the $\mathrm{LH}$ found in the serum comes exclusively from the implanted embryo. The majority of the LH in the serum of pregnant mice could be from the pituitary gland before and after ovulation or could be the result of an increase in pregnancy-related hormones. Herein, we characterised the presence of an LHCGR ligand/signal in mouse trophoblast, a question that, to date, had never been clearly answered. We also showed that the murine blastocyst expressed and produced an LH signal very early (a)
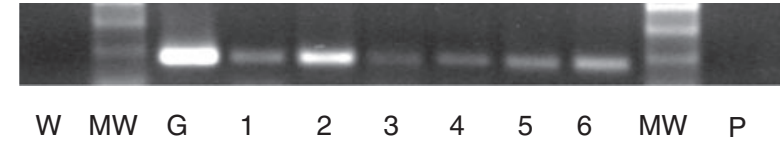

(b)

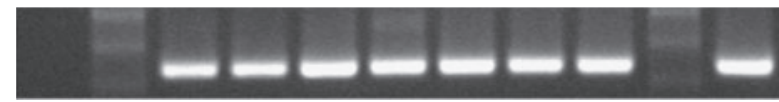

$\begin{array}{lllllllllll}W & M W & G & 1 & 2 & 3 & 4 & 5 & 6 & M W & P\end{array}$

(c)

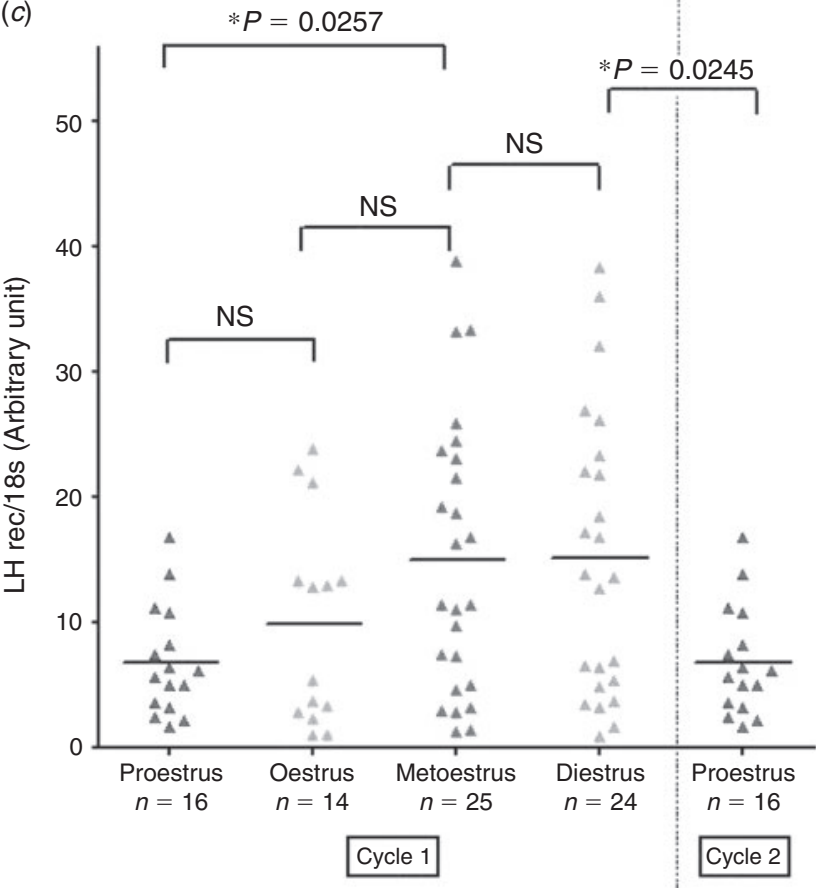

Fig. 5. (a) Expression of lhcgr transcripts (185 bp) at different stages of the oestrous cycle in BALB/c mice. Total endometrial RNA was extracted from one or two uteri at each stage (for metoestrus and dioestrus, $n=2$ ). (b) $\beta$-Actin transcripts $(250 \mathrm{bp})$ served as the housekeeping control. W, water replaced cDNA; MW, molecular weight scale; G, granulosa (positive control); Lane 1, pro-oestrus; Lane 2, oestrus; Lane 3, 4, metoestrus; Lane 5, 6, dioestrus; P, pancreas (negative control). (c) Quantification of endometrial lhcgr transcripts throughout the oestrous cycle. Results show the ratio of $l h c g r / 18 s$ expression (arbitrary units). Seventy-nine mice were used across the four stages of the oestrous cycle as follows: pro-oestrus $(n=16)$, oestrus $(n=14)$, metoestrus $(n=25)$ and dioestrus $(n=24)$ uteri. Black bars represent the mean for each group.

during its development, just before implantation, as demonstrated before in humans (Fishel et al. 1984) and recently confirmed by Ramu et al. (2011) as early as Day 2 . We showed that this LH signal is clearly bioactive. To our knowledge, this is the first demonstration of the production of a bioactive LH signal by the embryo in the murine species. Moreover, we detected an in vivo LH signal on gestation Day 7 in the sera of pregnant mice, embryos and implantations sites. There was a higher concentration of serum LH compared with that in embryos and at the implantation sites. We cannot exclude the possibility that this pattern could be explained by a potential external source of $\mathrm{LH}$ (of pituitary origin, for example). However, a study by Bachelot 
et al. (2009) showed that female mice lacking the prolactin receptor (PRLR) are sterile due to a failure of embryo implantation, which could be a consequence of decreased LHCGR expression in the corpus luteum and inadequate levels of progesterone. In that study, female mice treated with hCG showed de novo expression of $L H C G R$ in the corpora lutea that was not able to reverse the implantation defect (Bachelot et al. 2009) because, in mice, only prolactin is essential for the induction of the repression of progesterone catabolism, even if LHR are stimulated by hCG. Together, these findings explain the viability of the mouse KO for the LHCGR embryos (Huhtaniemi et al. 2002): the prolactin itself and maternal pituitary LH production allow the maintenance of sufficient progesterone levels to maintain pregnancy.

The mouse Leydig cell assay described by Dufau et al. (1974) and Ding and Huhtaniemi (1989) was used in the present study to test for LH-like activity. In the male, production of testosterone by Leydig cells is regulated by LH. As such, testosterone production in Leydig cells exposed to LH provides a useful, sensitive and specific method of measuring bioactive $\mathrm{LH}$ levels. Our results confirmed that an $\mathrm{LH} / \mathrm{hCG}$ signal is bioactive from Day 5 after fertilisation onward and this bioactivity increases significantly in the embryo culture medium after Day 7; however, LH bioactivity remains constant in the embryos during this time. Immediately upon synthesis, LH is secreted by the embryonic cells. It is therefore not surprising to find a constant level of LH bioactivity in the embryos. We also assessed LH bioactivity (LH or hCG-like) produced and secreted by mouse embryos. Although LH bioactivity remains constant within the embryo, the LH bioactivity accumulates markedly within the embryo culture medium over time.

The murine oestrous cycle is divided into the following four stages: pro-oestrus, oestrus (or ovulation), metoestrus and dioestrus (Allen 1922). These stages can be distinguished by characterisation of cells in vaginal smears (Allen 1922), the appearance of the vagina (Champlin et al. 1973) or histological modifications of the endometrium and vagina (Allen 1922; Putti and Varano 1979). The stages of the oestrous cycle have been described in the rat (Kaasjager 1969). We rigorously redefined each stage of the mouse oestrous cycle by examining vaginal smears to more accurately identify the stages, which is essential for characterising the endometrial biopsy. Vaginal smears were obtained every $5 \mathrm{~h}$ from BALB/c mice and stained with HE, as described by Allen (1922). This step is crucial because inaccurate characterisation of the endometrium can entirely skew the quantification of LHCGR expression and, hence, identification of the implantation window.

Studies performed over the past decade indicate that LHCGR is expressed in the human endometrium (Licht et al. 2003; Rao and Lei 2007); however, these findings are in contrast with those reported by Stewart et al. (1999). Zhang et al. (2001b) reported finding Lhcgr transcripts in the mouse reproductive tract. However, until now, this gene expression has not been quantified throughout the oestrous cycle. Using immunohistochemistry, we characterised LHCGR localisation in the endometrium and demonstrated intense labelling of the endometrial epithelium at every stage of the oestrous cycle. The labelling was particularly bright at the luminal surface of endometrial gland epithelial cells and in the lumen. This observation is very important, because this region of the endometrial surface facilitates binding of embryo signals such as the LH ligand. Pertinently, the endometrial epithelium is the first tissue encountered by the hatched embryo and LHCGR epithelial expression may reflect a pivotal role for this receptor during the adhesion phase of implantation. In addition, we used western blot analysis to examine LHCGR protein expression and found a $60-\mathrm{kDa}$ protein corresponding to the LHCGR protein present throughout all stages of the oestrous cycle.

Using RT-PCR, we examined endometrial Lhcgr expression using mRNA extracted at pro-oestrus, oestrus, metoestrus and dioestrus. Our findings confirmed and extended the results reported by Mukherjee et al. (1994) that indicate that Lhcgr transcripts are present in the endometrium and are expressed throughout the oestrous cycle. Real-time RT-PCR quantification with the TaqMan method was used to quantify the level of Lhcgr expression throughout the cycle. We found that Lhcgr transcripts increased throughout the oestrous cycle from a median of 5.855 arbitrary units (AU) at pro-oestrus to 9.041 $\mathrm{AU}$ at oestrus to $11.46 \mathrm{AU}$ at metoestrus, peaking at 13.72 AU at dioestrus. Indeed, the stages with higher Lhcgr expression correspond to the theoretical time of murine embryo implantation. After dioestrus, the expression level of Lhcgr dropped significantly back down to the pro-oestrus level of the next cycle. Our qRT-PCR results confirmed and extended findings in the mouse model reported by Bonnamy et al. (1990), who observed a cyclic variation in LHCGR binding to radiolabelled hCG in the rat endometrium. The increased Lhcgr expression at the time of implantation provides further support for a possible role of LHCGR signalling at the maternal-fetal interface during embryo implantation in mice. Our results also agree with those from a study by Chudgar et al. (2005), who found that LuRKO mice were not able to become pregnant after hormonal substitution or after orthotopic transplantation of wild-type ovaries. The contribution of uterine LHCGR signalling to the infertility of LuRKO mice was demonstrated by one group (Lin et al. 2005); however, conflicting results were published by Pakarainen et al. (2005), who were unable to show that orthotopic transplantation of wild-type ovaries into an LuRKO mouse resulted in impaired implantation. Nevertheless, although LHCGR has been identified previously in murine endometrium (Mukherjee et al. 1994) and an embryonic LH/ hCG-like signal has been detected throughout the pregnancy in the conceptus, placenta (Wide and Wide 1979) and plasma (Gidley-Baird 1977), these findings were never confirmed or have been the subject of controversy in the field (Roberts et al. 1996). In addition, to date the endometrial LHCGR ligand has never been identified in mouse blastocysts. The debate as to the importance of LHCGR for implantation has remained open because of the uncertainty as to whether the embryo secretes an LH/hCG-like signal as a ligand for endometrial LHCGR. Our results clearly confirm that the endometrium expresses LHCGR and demonstrate that the embryo is capable of communicating with endometrium through its production of a bioactive $\mathrm{LH} /$ hCG-like signal.

Our findings strongly suggest that the LHCGR system is complete at the time of implantation, with both the hormone and 
receptor being strongly expressed. In the future, an investigation of the binding of LH to the LHCGR should be undertaken to provide a better understanding of the LH-mediated cell signalling events that occur in the endometrium. It would also be interesting to identify the specific cells within the blastocyst (including the embryonic disc and associated membranes) that express LH mRNA and protein. A very critical experiment that would be interesting to perform would be to use a Cre/Lox system or a short interference RNA system to inactive gene expression of Lhcgr in the endometrium. This could elucidate definitively the controversy surrounding endometrial LHLHCGR cross-talk at the time of implantation.

In conclusion, the results of the present study demonstrate LHCGR expression by BALB/c mouse endometrial epithelium with increased expression at the time of implantation and further argue for a possible contribution of LHCGR function in the implantation process. We have also demonstrated that a highly bioactive LH signal is produced by embryos at the time of murine blastocyst implantation. On the basis of a role for LHCGR as the specific receptor for a blastocyst signal and the expression profile of Lhcgr during the oestrous cycle, we propose that an LH-LHCGR interaction may mediate cross-talk between the embryo and the endometrium during the implantation process. Better understanding of LHCGR signalling-mediated events during implantation will provide us with a more comprehensive picture of the normal human implantation process. Finally, this understanding will provide insight into the impact that hCG therapy has on medically assisted procreation in human patients with implantation, endometrial or embryonic disorders.

\section{Acknowledgements}

This work was supported by grants from Fonds pour la formation à la Recherche dans l'Industrie et dans l'Agriculture (FRIA, Belgium), Fonds de la Recherche Scientifique (FNRS, Belgium), Leon Fredericq Funds and FP6 Embryo Implantation Control (EMBIC) Network of Excellence.

\section{References}

Afshar, Y., Stanculescu, A., Miele, L., and Fazleabas, A. T. (2007). The role of chorionic gonadotropin and Notch1 in implantation. J. Assist. Reprod. Genet. 24, 296-302. doi:10.1007/S10815-007-9149-2

Allen, E. (1922). The oestrous cycle in the mouse. Am. J. Anat. 30, 297-371. doi:10.1002/AJA.1000300303

Aplin, J. D. (2000). The cell biological basis of human implantation. Best Pract. Res. Clin. Obstet. Gynaecol. 14, 757-764. doi:10.1053/BEOG. 2000.0116

Aplin, J. D., and Kimber, S. J. (2004). Trophoblast-uterine interactions at implantation. Reprod. Biol. Endocrinol. 2, 48. doi:10.1186/14777827-2-48

Bachelot, A., Beaufaron, J., Servel, N., Kedzia, C., Monget, P., Kelly, P. A., Gibori, G., and Binart, N. (2009). Prolactin independent rescue of mouse corpus luteum life span: identification of prolactin and luteinizing hormone target genes. Am. J. Physiol. Endocrinol. Metab. 297, E676-E684. doi:10.1152/AJPENDO.91020.2008

Berndt, S., Perrier d'Hauterive, S., Blacher, S., Pequeux, C., Lorquet, S., Munaut, C., Applanat, M., Herve, M. A., Lamande, N., Corvol, P., van den Brule, F., Frankenne, F., Poutanen, M., Huhtaniemi, I., Geenen, V., Noel, A., and Foidart, J. M. (2006). Angiogenic activity of human chorionic gonadotropin through $\mathrm{LH}$ receptor activation on endothelial and epithelial cells of the endometrium. FASEB J. 20, 2630-2632. doi:10.1096/FJ.06-5885FJE

Bonnamy, P. J., Benhaim, A., and Leymarie, P. (1990). Estrous cycle-related changes of high affinity luteinizing hormone/human chorionic gonadotropin binding sites in the rat uterus. Endocrinology 126, 1264-1269. doi:10.1210/ENDO-126-2-1264

Buxton, L. E., and Murdoch, R. N. (1982). Metabolic properties of mouse uterine endometrial cells after isolated with collagenase. Aust. J. Biol. Sci. 35, 277-286.

Cameo, P., Srisuparp, S., Strakova, Z., and Fazleabas, A. T. (2004) Chorionic gonadotropin and uterine dialogue in the primate. Reprod. Biol. Endocrinol. 2, 50. doi:10.1186/1477-7827-2-50

Carson, D. D., Bagchi, I., Dey, S. K., Enders, A. C., Fazleabas, A. T., Lessey, B. A., and Yoshinaga, K. (2000). Embryo implantation. Dev. Biol. 223, 217-237. doi:10.1006/DBIO.2000.9767

Champlin, A. K., Dorr, D. L., and Gates, A. H. (1973). Determining the stage of the estrous cycle in the mouse by the appearance of the vagina. Biol Reprod. 8, 491-494.

Chudgar, D., Lei, Z., and Rao Ch, V. (2005). Orthotopic transplantation of LH receptor knockout and wild-type ovaries. Life Sci. 77, 2656-2662. doi:10.1016/J.LFS.2005.03.024

Ding, Y. Q., and Huhtaniemi, I. (1989). Human serum LH inhibitor(s): behaviour and contribution to in vitro bioassay of LH using dispersed mouse Leydig cells. Acta Endocrinol. 121, 46-54.

Dufau, M. L., Mendelson, C. R., and Catt, K. J. (1974). A highly sensitive in vitro bioassay for luteinizing hormone and chorionic gonadotropin: testosterone production by dispersed Leydig cells. J. Clin. Endocrinol. Metab. 39, 610-613. doi:10.1210/JCEM-39-3-610

Edwards, R. G. (2006). Human implantation: the last barrier in assisted reproduction technologies? Reprod. Biomed. Online 13, 887-904. doi:10.1016/S1472-6483(10)61039-5

Fishel, S. B., Edwards, R. G., and Evans, C. J. (1984). Human chorionic gonadotropin secreted by preimplantation embryos cultured in vitro. Science 223, 816-818. doi:10.1126/SCIENCE.6546453

Fluhr, H., Krenzer, S., Deperschmidt, M., Zwirner, M., Wallwiener, D., and Licht, P. (2006). Human chorionic gonadotropin inhibits insulin-like growth factor-binding protein-1 and prolactin in decidualized human endometrial stromal cells. Fertil. Steril. 86, 236-238. doi:10.1016/ J.FERTNSTERT.2005.12.031

Ghosh, D., and Sengupta, J. (1998). Recent developments in endocrinology and paracrinology of blastocyst implantation in the primate. Hum Reprod. Update 4, 153-168. doi:10.1093/HUMUPD/4.2.153

Gidley-Baird, A. A. (1977). Plasma progesterone, FSH and LH levels associated with implantation in the mouse. Aust. J. Biol. Sci. 30, 289-296.

Han, S. W., Lei, Z. M., and Rao, C. V. (1996). Up-regulation of cyclooxygenase-2 gene expression by chorionic gonadotropin during the differentiation of human endometrial stromal cells into decidua Endocrinology 137, 1791-1797. doi:10.1210/EN.137.5.1791

Han, S. W., Lei, Z. M., and Rao, C. V. (1999). Treatment of human endometrial stromal cells with chorionic gonadotropin promotes their morphological and functional differentiation into decidua. Mol. Cell. Endocrinol. 147, 7-16. doi:10.1016/S0303-7207(98)00240-8

Holland, P. M., Abramson, R. D., Watson, R., and Gelfand, D. H. (1991). Detection of specific polymerase chain reaction product by utilizing the $5^{\prime} \rightarrow 3^{\prime}$ exonuclease activity of Thermus aquaticus DNA polymerase. Proc. Natl Acad. Sci. USA 88, 7276-7280.

Huhtaniemi, I., Zhang, F. P., Kero, J., Hamalainen, T., and Poutanen, M. (2002). Transgenic and knockout mouse models for the study of luteinizing hormone and luteinizing hormone receptor function. Mol. Cell. Endocrinol. 187, 49-56. doi:10.1016/S0303-7207(01)00698-0

Jensen, J. D., and Odell, W. D. (1988). Identification of LH/hCG receptors in rabbit uterus. Proc. Soc. Exp. Biol. Med. 189, 28-30. 
Jurisicova, A., Antenos, M., Kapasi, K., Meriano, J., and Casper, R. F. (1999). Variability in the expression of trophectodermal markers betahuman chorionic gonadotrophin, human leukocyte antigen-G and pregnancy specific beta-1 glycoprotein by the human blastocyst. Hum. Reprod. 14, 1852-1858. doi:10.1093/HUMREP/14.7.1852

Kaasjager, W. A. (1969). Effect of progesterone and hypothalamic stimulation on LH release at different stages of the oestrous cycle in the rat. J. Endocrinol. 43, xix-xx.

Kayisli, U. A., Selam, B., Guzeloglu-Kayisli, O., Demir, R., and Arici, A. (2003). Human chorionic gonadotropin contributes to maternal immunotolerance and endometrial apoptosis by regulating Fas-Fas ligand system. J. Immunol. 171, 2305-2313.

Khan, N. A., Khan, A., Savelkoul, H. F., and Benner, R. (2001). Inhibition of diabetes in NOD mice by human pregnancy factor. Hum. Immunol. 62, 1315-1323. doi:10.1016/S0198-8859(01)00368-8

Khil, L. Y., Jun, H. S., Kwon, H., Yoo, J. K., Kim, S., Notkins, A. L., and Yoon, J. W. (2007). Human chorionic gonadotropin is an immune modulator and can prevent autoimmune diabetes in NOD mice. Diabetologia 50, 2147-2155. doi:10.1007/S00125-007-0769-Y

Lessey, B. A. (2000). Endometrial receptivity and the window of implantation. Best Pract. Res. Clin. Obstet. Gynaecol. 14, 775-788. doi:10.1053/ BEOG.2000.0118

Licht, P., Russu, V., Lehmeyer, S., and Wildt, L. (2001). Molecular aspects of direct $\mathrm{LH} / \mathrm{hCG}$ effects on human endometrium: lessons from intrauterine microdialysis in the human female in vivo. Reprod. Biol. 1, 10-19.

Licht, P., Russu, V., Lehmeyer, S., Moll, J., Siebzehnrubl, E., and Wildt, L. (2002). Intrauterine microdialysis reveals cycle-dependent regulation of endometrial insulin-like growth factor binding protein-1 secretion by human chorionic gonadotropin. Fertil. Steril. 78, 252-258. doi:10.1016/ S0015-0282(02)03226-0

Licht, P., von Wolff, M., Berkholz, A., and Wildt, L. (2003). Evidence for cycle-dependent expression of full-length human chorionic gonadotropin/ luteinizing hormone receptor mRNA in human endometrium and decidua. Fertil. Steril. 79(Suppl. 1), 718-723. doi:10.1016/S0015-0282(02)04822-7

Licht, P., Fluhr, H., Neuwinger, J., Wallwiener, D., and Wildt, L. (2007). Is human chorionic gonadotropin directly involved in the regulation of human implantation? Mol. Cell. Endocrinol. 269, 85-92. doi:10.1016/ J.MCE.2006.09.016

Lin, D. X., Lei, Z. M., Li, X., and Rao Ch, V. (2005). Targeted disruption of $\mathrm{LH}$ receptor gene revealed the importance of uterine LH signaling. Mol. Cell. Endocrinol. 234, 105-116. doi:10.1016/J.MCE.2004.09.011

Mukherjee, D., Manna, P. R., and Bhattacharya, S. (1994). Functional relevance of luteinizing hormone receptor in mouse uterus. Eur. J. Endocrinol. 131, 103-108. doi:10.1530/EJE.0.1310103

Norwitz, E. R., Schust, D. J., and Fisher, S. J. (2001). Implantation and the survival of early pregnancy. N. Engl. J. Med. 345, 1400-1408. doi:10.1056/NEJMRA000763

Pakarainen, T., Zhang, F. P., Poutanen, M., and Huhtaniemi, I. (2005). Fertility in luteinizing hormone receptor-knockout mice after wild-type ovary transplantation demonstrates redundancy of extragonadal luteinizing hormone action. J. Clin. Invest. 115, 1862-1868. doi:10.1172/ JCI24562

Pan, H., Zhu, L., Deng, Y., and Pollard, J. W. (2006). Microarray analysis of uterine epithelial gene expression during the implantation window in the mouse. Endocrinology 147, 4904-4916. doi:10.1210/EN.2006-0140

Paria, B. C., Reese, J., Das, S. K., and Dey, S. K. (2002). Deciphering the cross-talk of implantation: advances and challenges. Science 296, 2185-2188. doi:10.1126/SCIENCE.1071601

Perrier d'Hauterive, S., Charlet-Renard, C., Berndt, S., Dubois, M., Munaut, C., Goffin, F., Hagelstein, M. T., Noel, A., Hazout, A., Foidart, J. M., and
Geenen, V. (2004). Human chorionic gonadotropin and growth factors at the embryonic-endometrial interface control leukemia inhibitory factor (LIF) and interleukin 6 (IL-6) secretion by human endometrial epithelium. Hum. Reprod. 19, 2633-2643. doi:10.1093/HUMREP/DEH450

Perrier d'Hauterive, S., Charlet-Renard, C., Dubois, M., Berndt, S., Goffin, F., Foidart, J. M., and Geenen, V. (2005). Human endometrial leukemia inhibitory factor and interleukin-6: control of secretion by transforming growth factor-beta-related members. Neuroimmunomodulation 12, 157-163. doi:10.1159/000084848

Psychoyos, A. (1986). Uterine receptivity for nidation. Ann. N. Y. Acad. Sci. 476, 36-42. doi:10.1111/J.1749-6632.1986.TB20920.X

Putti, R., and Varano, L. (1979). Histological and histochemical modifications of the uterine and vaginal mucosa of the mouse during the oestrus cycle. Basic Appl. Histochem. 23, 25-37.

Ramu, S., Acacio, B., Adamowicz, M., Parrett, S., and Jeyendran, R. S. (2011). Human chorionic gonadotropin from Day 2 spent embryo culture media and its relationship to embryo development. Fertil. Steril. 96, 615-617. doi:10.1016/J.FERTNSTERT.2011.06.035

Rao, C. V., and Lei, Z. M. (2007). The past, present and future of nongonadal $\mathrm{LH} / \mathrm{hCG}$ actions in reproductive biology and medicine. Mol. Cell. Endocrinol. 269, 2-8. doi:10.1016/J.MCE.2006.07.007

Roberts, R. M., Xie, S. C., and Mathialagan, N. (1996). Maternal recognition of pregnancy. Biol. Reprod. 54, 294-302. doi:10.1095/BIOLRE PROD54.2.294

Sherwin, J. R., Sharkey, A. M., Cameo, P., Mavrogianis, P. M., Catalano, R. D., Edassery, S., and Fazleabas, A. T. (2007). Identification of novel genes regulated by chorionic gonadotropin in baboon endometrium during the window of implantation. Endocrinology 148, 618-626. doi:10.1210/ EN.2006-0832

Stewart, E. A., Sahakian, M., Rhoades, A., Van Voorhis, B. J., and Nowak, R. A. (1999). Messenger ribonucleic acid for the gonadal luteinizing hormone/human chorionic gonadotropin receptor is not present in human endometrium. Fertil. Steril. 71, 368-372. doi:10.1016/S00150282(98)00453-1

Sunder, S., and Lenton, E. A. (2000). Endocrinology of the peri-implantation period. Best Pract. Res. Clin. Obstet. Gynaecol. 14, 789-800. doi:10.1053/ BEOG.2000.0119

Wide, L., and Wide, M. (1979). Chorionic gonadotrophin in the mouse from implantation to term. J. Reprod. Fertil. 57, 5-9. doi:10.1530/JRF.0. 0570005

Zenclussen, A. C., Gerlof, K., Zenclussen, M. L., Ritschel, S., Zambon Bertoja, A., Fest, S., Hontsu, S., Ueha, S., Matsushima, K., Leber, J., and Volk, H. D. (2006). Regulatory T cells induce a privileged tolerant microenvironment at the fetal-maternal interface. Eur. J. Immunol. 36, 82-94. doi:10.1002/EJI.200535428

Zhang, F. P., Poutanen, M., Wilbertz, J., and Huhtaniemi, I. (2001a). Normal prenatal but arrested postnatal sexual development of luteinizing hormone receptor knockout (LuRKO) mice. Mol. Endocrinol. 15, 172-183. doi:10.1210/ME.15.1.172

Zhang, M., Shi, H., Segaloff, D. L., and Van Voorhis, B. J. (2001b). Expression and localization of luteinizing hormone receptor in the female mouse reproductive tract. Biol. Reprod. 64, 179-187.

Ziecik, A. J., Stanchev, P. D., and Tilton, J. E. (1986). Evidence for the presence of luteinizing hormone/human chorionic gonadotropin-binding sites in the porcine uterus. Endocrinology 119, 1159-1163. doi:10.1210/ ENDO-119-3-1159

Zygmunt, M., Herr, F., Keller-Schoenwetter, S., Kunzi-Rapp, K., Munstedt, K., Rao, C. V., Lang, U., and Preissner, K. T. (2002). Characterization of human chorionic gonadotropin as a novel angiogenic factor. J. Clin. Endocrinol. Metab. 87, 5290-5296. doi:10.1210/JC.2002-020642 